\title{
Research on the Drapery in Ancient Greek Sculptures
}

\author{
Jing Chen ${ }^{1} \&$ Yiqiang $\mathrm{Cao}^{1,2}$ \\ ${ }^{1}$ Fashion \& Art Design Institute, Donghua University, Shanghai, China \\ ${ }^{2}$ Advanced School of Art and Humanities, China Academy of Art, Hangzhou, China \\ Correspondence: Yiqiang Cao, Fashion \& Art Design Institute, Donghua University, 1882 West Yan'an Road, \\ Changning District, Shanghai, China. Tel: 86-135-8887-9825. E-mail: 0111010@ caa.edu.cn
}

Received: April 13, $2021 \quad$ Accepted: April 29, $2021 \quad$ Online Published: May 31, 2021

doi:10.5539/ass.v17n6p29 URL: https://doi.org/10.5539/ass.v17n6p29

\begin{abstract}
Sculpture in the ancient Greek period has an extremely lofty position in the history of Western art, and the drapery is one of the most important modeling characteristics of ancient Greek sculpture. This article summarizes the style evolution of drapery in ancient Greek sculptures through the performance of ancient Greek costume characteristics and dressing methods in sculptures. And through the drapery produced by the different postures of the human body in the sculptures, it is explored how the ancient Greek artists used drapery to show the dialectical relationship between clothing, the human body and the posture, thereby shaping the beauty model of classical clothing.
\end{abstract}

Keywords: Ancient Greek sculpture, drapery, style

When Winkelman studied ancient Greek art, he juxtaposed drapery with nature, contours and expressions, and considered it to be one of the most prominent features of ancient Greek sculpture. As he said, "By drapery is understood all that art teaches of covering the nudities, and folding the garments; and this is the third prerogative of the ancients." The drapery in the sculptures of the ancient Greek period not only reflect the clothing form of this period, but also show the artist's aesthetic taste, artistic technique and creativity.

\section{The Characteristics of Clothing in Ancient Greece}

The sculpture art of the ancient Greek period mainly used marble, bronze, clay, wood, gold, and ivory as materials, and most of the sculptures that can survive to this day are stone carvings. Among these stone sculptures, the meticulous depictions of the costume styles of the characters are mainly concentrated in the 7th century BC to the 2th century BC. Ancient Greek clothing in this period has non-structural characteristics, usually using a rectangular cloth to drape, wrap, tie around the body, and fix it in place with pins, belts, etc., to create a large number of draping effects. From the perspective of dress form, ancient Greek clothing is divided into hanging style and wrapping style. Among the clothes in the form of draping, chiton and peplos are the most representative.

\subsection{Chiton}

Chiton was a type of broad robe most commonly worn by men and women in ancient Greece. Its fabrics were mainly woolen fabrics and linens, and later Indian cotton and smoother and lighter silk fabrics were also used. In daily life, chiton is divided into many forms. The most common sculptures are Doric Chiton (Figure 1) and Ionic Chiton (Figure 2), both of which are different in style. Doric Chiton usually uses a thicker rectangular wool fabric with the long side folded outward, the amount of fold is about the length from the neck to the waistline, and the two short sides of the rectangular fabric are folded in half around the body. The position of the shoulders are fixed with pins, and the waist belt is tied to gather the loose fabric at the waist; or two pieces of fabric are placed on the front and back of the body, the positions of the shoulders are fixed with pins, and the stitching fabric on either side of the body, there is another way to tie the doric chiton belt, that is, use a double waist belt, one at the high waist and the other at the low waist. The two layers of longitudinal pleats make the shape of draped folds more complicated. The Ionic Chiton is made by folding the short edge of a rectangular fabric in half, extend the arm at the side seam, and stitching the rest together with 8-12 safety pins to fix fabric around the shoulders and the arms. In order to make it easier for the wearer to move, the spacious Ionic Chiton often uses a string to tie the "sleeves" to fix it. The length of the two chiton almost hangs down to the ankle or the ground, but for soldiers or the ancient Greek people engaged in manual labor, too long clothing will bring a lot of 
inconvenience. Therefore, the Greek people will use pins or straps to wear excessively long fabrics are pulled up and fixed to a position above the knees, and even short chiton are worn.

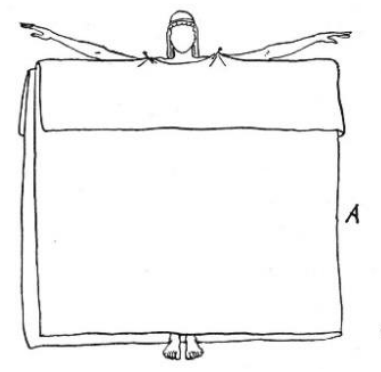

1(a) Doric Chiton's way of dressing

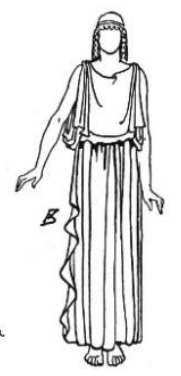

Figure 1. Doric Chiton

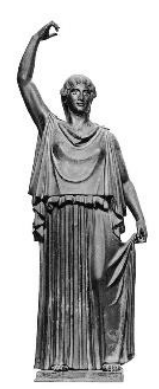

1(b) Ancient Greek Sculpture

Here 1. Doic Chiton

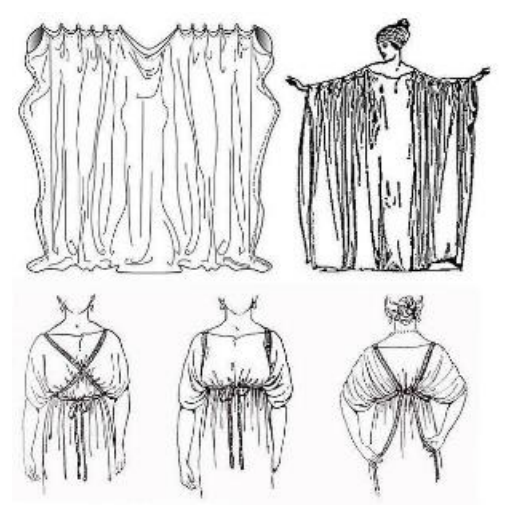

2(a) Ionic Chiton's way of dressing

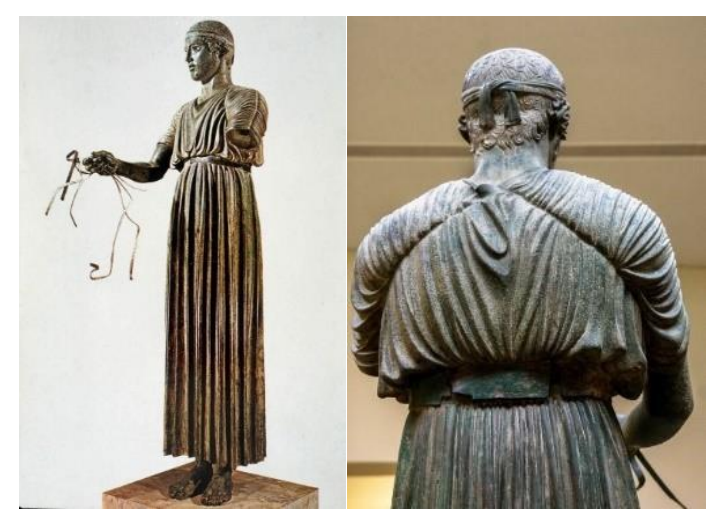

2(b) Charioteer of Delphi (c. 470 BC)

Figure 2. Ionic Chiton

\subsection{Peplos}

Peplos is a type of robe worn by Greek women (Figure 3). The word means "blanket worn on the body" fixed with a pin. In "Homer's Epic", peplos is a kind of daily garment, usually composed of a large rectangular wool fabric without cutting and sewing. The wearer fixes it on the shoulders with pins or buckles and folds it above the waist to create a drape or flap-like effect. It is worth mentioning that since Chiton appeared in ancient Greek art in the middle of the 6th century $\mathrm{BC}$, he once replaced peplos. However, in the early classical era (approximately 500-450 BC), especially after the end of the Hippo War in $480 \mathrm{BC}$, peplos reappeared in ancient Greek art, such as the goddess in public and monumental sculptures, often appear wearing peplos. Some scholars speculate that the large number of peplos in sculptures in the early classical era is not a true reflection of the dressing habits of the time, but a symbol. Peplos may be a kind of clothing worn in memorial ceremonies, a symbol of ancient Greek traditional clothing.
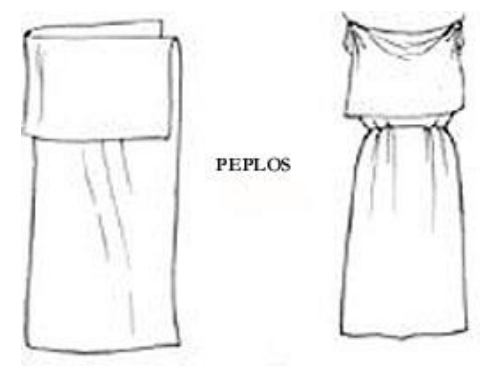

3(a) Peplos' s way of dressing

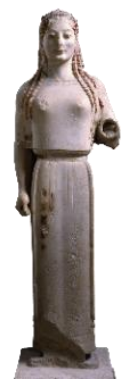

3(b) Peplos Kore (c.530 BC)

Figure 3. Peplos 


\subsection{Himation \& Chlamys}

In the wrapped form of clothing, there are two kinds of outerwear representative. One is the largest worn Greek cloth was known as the Himation (Figure 4), and the other is the shorter cloak chlamys (Figure 5). Especially outdoors, men and women in ancient Greece usually covered the Chiton with an additional coat. Among them, himation is a large rectangular piece of wool fabric, in a diagonal way over the torso, carried on one side of the shoulder and arm, and wrapped around the body. Another short cloak chlamys is made of dark wool. Usually a rectangular piece of fabric is draped on the left shoulder, and then fixed with a pin near the right neck. The main wearers of this short cloak are usually young men and soldiers from ancient Greece. When men in ancient Greece wore these two forms of outerwear, they sometimes draped them alone without wearing Chiton, thus revealing part of their chest, shoulders and arms are exposed.

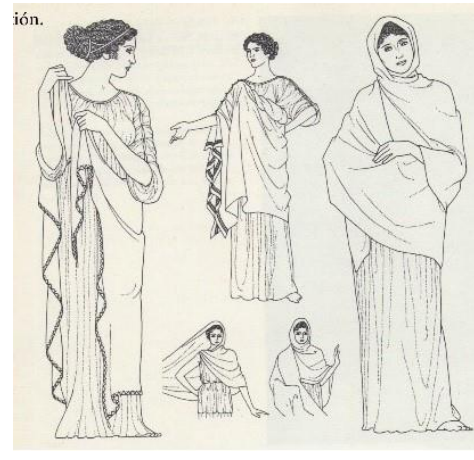

Figure 4. Himation

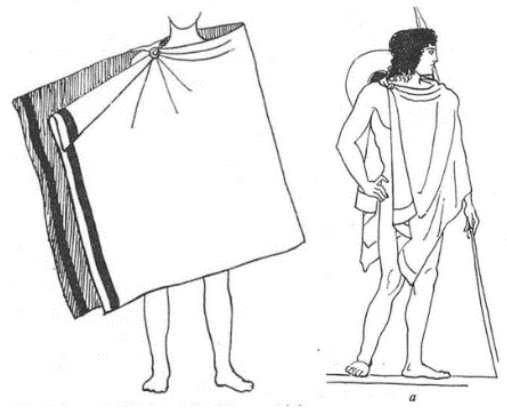

Figure 5. Chlamys

It can be seen from the above forms of clothing that the clothing of the ancient Greek period was characterized by looseness and lightness. Under the influence of factors such as the fabric type and volume of the clothing, the shape of the drape and folds produced by the clothing will also change, forming a rich interaction with the shape and movement of the human body. These factors provide sufficient objective conditions for the expression of drapery in the medium of sculpture, so that drapery become one of the basic appearance elements of Greek figure sculptures.

\section{The Evolution of the Style of Drapery in Ancient Greek Sculpture}

\subsection{Archaic Greece}

As we all know, the ancient Greek sculptures were influenced by ancient Egyptian sculptures to a large extent, and their styles tend to be geometrical and conceptual, and the draperies are also the same. A typical example is the "Lady of Auxerre" (c. 650 BC) (Figure 6). The statue figure wears a short shawl, and a long skirt close to the body is decorated with geometric patterns of different shapes and a belt is tied around the waist. This statue hardly expresses the wrinkles of the clothes and the hints of the fabric material. It just imitates the ancient Egyptian sculptures and "marks" the existence of the fabric in a geometrical way. "Hera of Samos" (c. 570-60 BC) (Figure 7), this work is considered to be one of the first ancient Greek sculptures to show obvious clothing folds. The sculptor intended to express two things at the same time: light and soft clothing fabrics and the undulating silhouette of the human body under the clothing. The smooth folds of the clothes undulate slightly from the shoulders and arms along the body, and spread out to the feet through the chest, abdomen, and buttocks. The texture of the fabric was carefully rendered by the vertical lines on the long skirt, and these lines are evenly close to the body, like the second skin. By the "Kore" (c. 520 BC) (Figure 8), we can see that ancient Greek sculptures began to express more realistically the structure of clothing, and the details of the clothing were also richer. The girl in the sculpture wears a Himation (mantle), and the inner layer is wearing an Ionic Chiton(light linen). In this work, the sculptor not only pays attention to the depiction of the pendant folds of fabric and intricate patterns in the wrap-around clothing, but also tries to distinguish different clothing styles and textures by using a variety of garment lines. Whether in terms of realism or aesthetics, this work has a significant development in the depiction of drapery compared to "Hera of Samos", which was painted about half a century ago. 


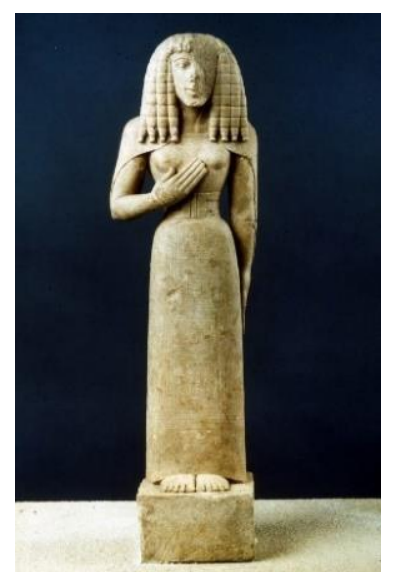

Figure 6. Lady of Auxerre

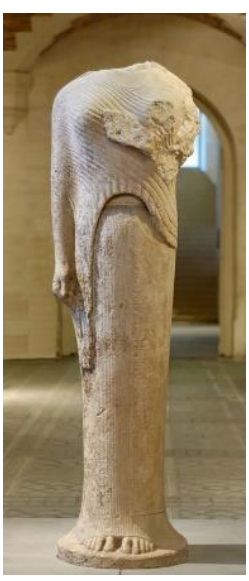

Figure 7. Hera of Samos

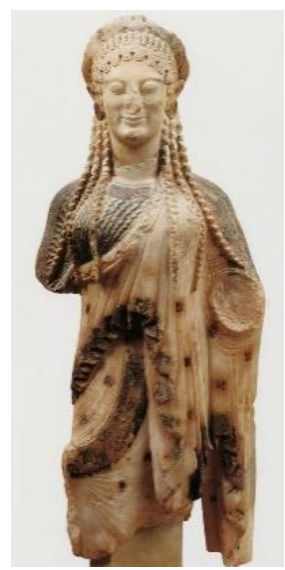

Figure 8. Kore

The above three sculptures belong to the works of the ancient Greek period. Their overall style tends to be stylized, geometrical, and conceptual, and their representations of human bodies and clothing are relatively rigid. However, their realistic skills have clearly developed. By comparing the ancient Greek vase paintings of the same period, it can be found that the ancient Greeks' clothing did not change significantly during this period. It can be seen that it is not the clothing itself that really has an impact on the form of clothing in sculptures of this period, but mainly the changes in the technique and style of the sculpture. Although the draper in this work is more conceptual, it still reflects the sculptor's observation of the details of life and concise artistic expression.

\subsection{Classical Greece}

In the process of the development of ancient Greek sculpture, the artist's techniques of expressing clothing developed simultaneously with their techniques of expressing the beauty of the human body. Since the classical period, ancient Greek sculpture has entered the peak of naturalism and ideal beauty. At this time, the sculptor began to deal with an important proposition, that is, the harmony and unity between clothing and the human body, and drapery are the link between the two parties. The sculptors in the classical period discovered and used the law of contrapposto to shape the human body. As the posture of the human body became richer, the clothing form in the sculpture gradually changed, and the form of clothing fold became more abundant. Whether it is embossed or rounded, the drapery has their own unique expression techniques and intentions. In terms of clothing materials, in addition to wool and linen, fabrics such as light and thin silk were also adopted by the Greeks. This provides a wider space for the sculptor to express the free movement of fabrics and the interaction between clothing and the human body.

The relief "Marble grave stele of a little girl" (c. 450-40 BC) (Figure 9) and "Erechtheion Caryatid" (c. 421-06 BC) (Figure 10) are representative of sculpture performance clothing in the classical period. What these two sculptures have in common is that the figures are standing in opposite and balanced positions. They are dressed in peplos, and The shoulders on both sides constitute two supporting points, so the drape shaped clothes pattern will naturally appear on the upper body of the character. The thigh and knee on one side are more prominent, forming a secondary support point below the waist, forming the effect of fabric wrapping the body. The difference is that the former "Marble grave stele of a little girl" is a relief, which belongs to the early classical style, and its clothes lines are concise. The sculptor enriched the plane depth of the work and enhanced the sense of volume of the object through different levels of longitudinal and vertical clothing patterns in the same plane.

The "Erechtheion Caryatid" is not only a sculpture, but also a pillar part of the building. Therefore, the drapery not only enhances the vividness and beauty of the object, but also seems to support the body, just like the sculpture as a pillar bears the weight above the eaves of the building. At the same time, the drapery also has the function of the column groove, which can make the clothes pattern on the column form a rich light and shadow effect under natural light conditions, adding a sense of rhythm and elegance to the visual appearance of the building. In fact, according to Vitruvius, the grooves on the pillars of ancient Greek temples were designed to mimic the pleats of ladies' robes. 


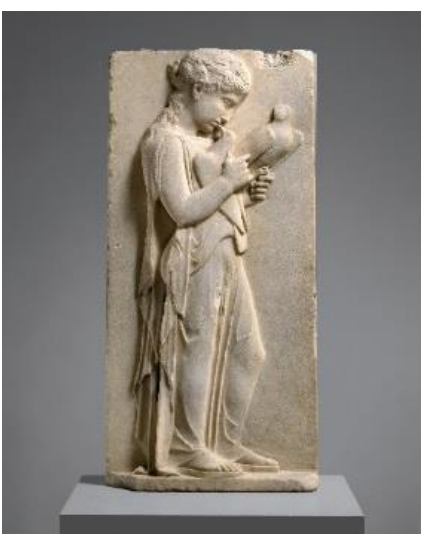

Figure 9. Marble grave stele of a little girl

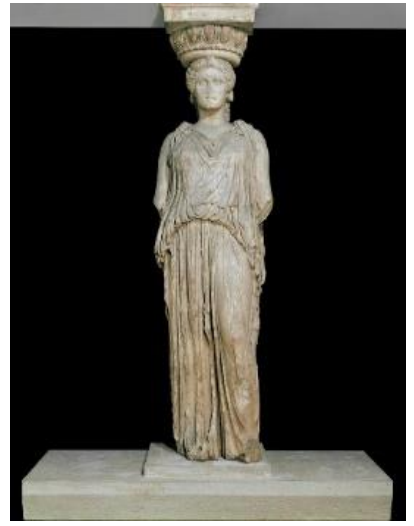

Figure 10. Erechtheion Caryatid

At the same time, after the development of the classical period, the relationship between clothing and human body in sculpture is no longer a simple relationship between covering and support, but an organic whole of life. Sculptors impart dynamic, rhythm and vitality to the human body through the expression of clothing patterns, which has become an almost indispensable form element of female sculpture. Numerous Victory statues such as "Nike of Paionios" (c.425-20 BC) (Figure 11) are representative of them. Such statues are enshrined in temples and public buildings for worship and appreciation. Their costumes are idealized and divine, and their drapery are also a product of stylization.The fluttering long skirts forms undulating folds are so realistic and beautiful, as if the graceful goddess of victory wearing a light-textured shirt and walking slowly towards us from the marble. This is the typical way of expressing drapery in sculptures in the classical period. As Winkelman said: "The Greek Drapery, in order to help the Contour, was, for the most part, taken from thin and wet garment, which of course clasped the body, and discovered the shape."

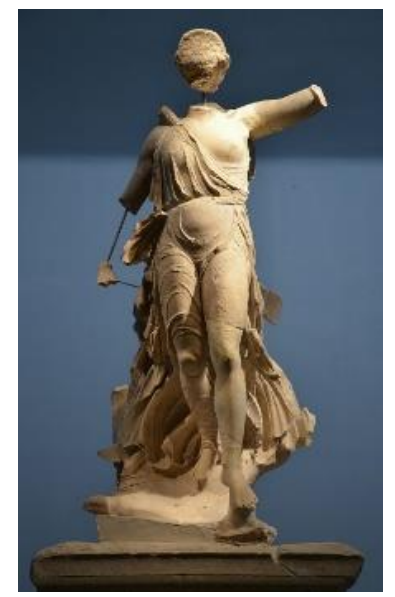

Figure 11. Nike of Paionios

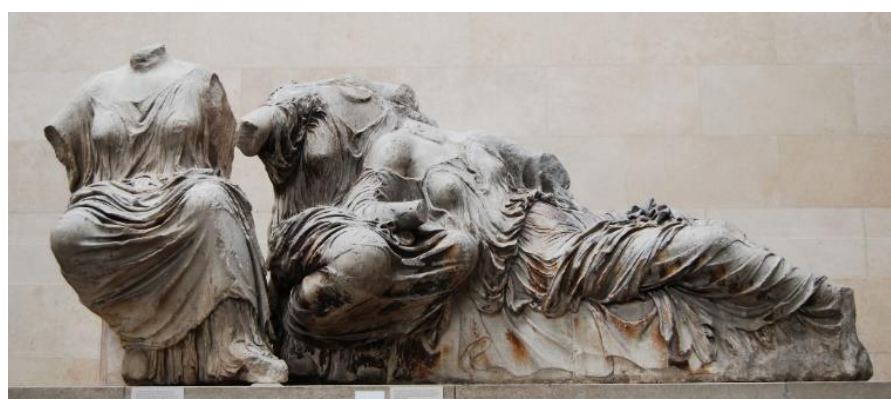

Figure 12. Three goddesses on the east gable of the Parthenon

The "drapery of wet-look" that Winkelman called became the unique style of ancient Greek sculptures, and had a profound influence on later Indian and Chinese art. In the sculptures of the classical period, the "drapery of 
wet-look" was applied to the extreme, and it was the sculpture of three goddesses on the east gable of the Parthenon(c.438-32 BC) (Figure 12), this work embodies what Winkelman calls the Greek drapery, light and thin clothing clings to the human body, and the texture of the clothing is like a stream, flowing and rotating on the body, forming a changeable and beautiful shape: "The smaller foldings spring gradually from the larger ones, and in them are loft again, with a noble freedom, and gentle harmony of the whole, without hiding the correct Contour." The human body, clothing, and drapery are completely integrated, allowing viewers to completely forget that they are not facing the warm human body and soft fabrics, but are actually hard and cold marble. As far as the relationship between the drapery, body and clothing is concerned, this work fully illustrates that in the classical period from about 440-30 BC, the artist no longer simply regarded clothing as a wrapper and cover for the human body, but through clothing to express a more perfect and more attractive human body. The role of clothing changed from conceal the human body to revealing the human body. And this kind of human body revealed by clothing has more ideal and beautiful charm and abundant vitality than the naked human body.

In addition to the above sculptures showing standing and sitting postures, the figures in the sculptures of the Classical period also appeared in richer and more diverse gestures, such as dance, and their drapery form were also more decorative and expressive. The Figure 13 shows an ancient Roman copy of an original ancient Greek work. The original work is about $425-400 \mathrm{BC}$, which is the late classical period. This relief shows the dancing posture of Maenads, the female entourage of Dionysus. In addition to the expression of the light and thin fabric and the close-fitting texture of the human body, the most prominent feature of the drapery in this sculpture is the dancing shape and decorative line patterns. The fluttering clothing, as if possessing its own will, forms a vortex like a sea wave. Compared with previous works, the clothes patterns in this sculpture are no longer restricted by the posture of the human body, but the external manifestation of the inner mental state and vitality of the characters, becoming a relatively independent material carrier and formal element. It allows the theme of "madness" to be expressed in an aesthetic way, and its expressiveness has surpassed the original image of the character. Therefore, as far as drapery modelling are concerned, the greatest inspiration from this work is that although the drapery in ancient Greek sculptures are based on the artist's observation and imitating nature, their artistic charm and aesthetic value are not only derived from the artist's observation of clothes, but from the artist's idea of beauty. After the sculptor's design, the clothes pattern has its own independent vitality and formal value. At the same time, it also gives infinite artistic charm to the relatively simple style of ancient Greek clothing, allowing later generations give out romantic imagination about the elegant and agile beauty of ancient Greek costume, thus inspiring later generation of artistic creation and clothing design inspiration.

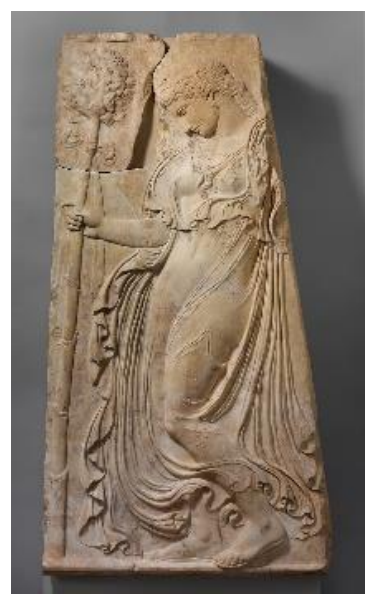

Figure 13. Dancing Maenad Roman copy of Greek original attributed to Kallimachos circa 425-400 BCE at the Metropolitan Museum of Art

It is worth noting that it was not until about $370 \mathrm{BC}$ that a naked female figure appeared in ancient Greece. Before this, artists tried their best to use clothing patterns to imply the beauty of women's bodies. In sculptures that express complex dynamics, the texture of thin, transparent, and soft fabrics is expressed to the extreme. The sculptor uses clothing patterns to show the relationship between clothing and the human body, they use expressive techniques to transform static into movement, and externalize the emotion and vitality of the characters into movement and rhythm of lines. This technique had an important influence on the artists of the Renaissance, and the German art historian Aby Warburg called it "Appendage in motion." 


\subsection{Hellenistic Greece}

In the sculptures of the Hellenistic period, the expression of the noble ideal beauty in the classical period is gradually fading, replaced by the humanized and secularized individual expression. In terms of drapery, statues in the Hellenistic period are more realistic and complex. Observation of nature and exquisite craftsmanship enabled sculptors of this period to more adeptly express the complex effects of various clothing materials covering the body. In the "Running Niobid" (c.3th BC) (Figure 14), the sculptor vividly represented the clothes worn by this running woman, the thin texture of chiton is close to the body, the lines of the clothes are delicate and smooth. The Himation draped on the outer layer has relatively thicker fabrics, rougher lines, obvious transitions between the pleats, and a tough shape. Under the dynamics of running, both pieces of clothing are fluttering in the wind, and the different forms of fluttering further distinguish their materials.

Due to the colonization and expansion of Greek civilization during the Hellenistic period, the style of ancient Greek sculpture spread to areas outside the Greek peninsula. The drapery in sculptures of this period were more diversified in clothing forms and expression techniques, reflecting the inclusiveness and extensive influence of ancient Greek civilization. A statue of an unknown woman, unearthed in the Phocaea region of Ionian (located on the west coast of Turkey) (Figure 15), the robe hangs down to the ground, and layers of folds are accumulated around the instep. As far as we can see, the body was completely covered by clothes, forming an abstract and rhythmic pattern. Different from the sculpture in the classical period, the author of this sculpture focused on imitating the form of drapery itself, but did not intend to express the beauty of the human body covered by clothing through the drapery.

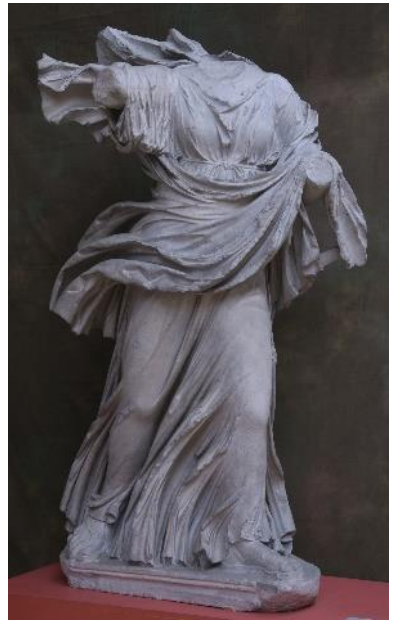

Figure 14. Running Niobid

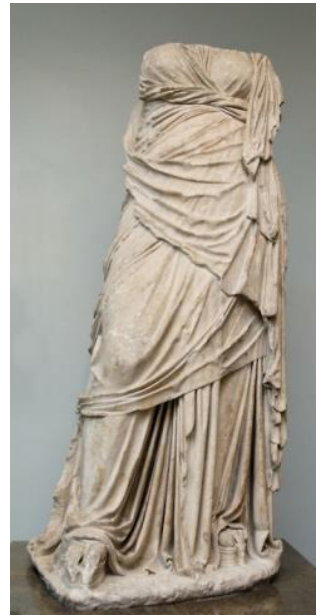

Figure 15. Unknown woman

\section{The Independent Value of Drapery}

The independent value of the garment pattern here refers to the value of the fabric's pleats in the structure and form of the sculpture after the fabric is separated from the human body. In this case, the shape of drapery is no longer directly related to the structure and dynamics of the human body. Its value lies in making the flat fabric have a three-dimensional effect, through the change of light and shadow to create a rich visual effect, making the drapery contrast with the healthy and elegant human body and complement each other.

In ancient Greek sculptures, male nudes appeared earlier. Therefore, the separation of fabric and human body appeared earlier in male sculptures. "Lapith and Centaur" (c.447-42 BC) (Figure 16) is one of the series of reliefs on the stalls on the southern wall of the Parthenon. Lapith is wearing a himation, and the fabric is hung on both arms, forming a typical two-point supporting pattern effect. In this fighting scene, himation served as the background of the human body, the light and shadow on the drapery heighten the intense and tense atmosphere of the fight. Similar scenes of war are found in the reliefs of the Altar of Zeus build around 180-160 BC (Figure 17). Standing on the right is Zeus, wearing a cloak to emphasize his status as the main god. The two works are nearly three hundred years apart, but they both use similar designs. The difference is that the former cloak is semi-circular, and the fold lines are smooth and complete, while the cloak of the latter is more dramatic, with the folds changing tortuously and intensely. These differences also reflect the style change of ancient Greek sculpture from the classical era to the Hellenistic era. 
In female nude sculptures, drapery have similar values. It is said that the sculptor Praxiteles in the 4th century BC created the naked female goddess of love "Aphrodite of Knidos" (Figure 18). Although the original work of the statue has been lost, there are still many copies and imitations. These works have a certain commonality in the conception, for example, a clay pot always appeared next to Aphrodite, covered with the clothes she took off. The combination of clothing and clay pots provides the necessary support for the characters' arms. The clothes hang down to form zigzag folds, casting a complex light and shadow effect on the marble surface, in contrast to the smooth human body. The famous sculpture "Aphrodite of Milos" (c.130-100 BC) (Figure 19) also uses a similar design, the cloth piled up on the lower body of the character seems to have just slipped from the upper body. The soft skin and the pleats form a strong texture and visual contrast. To a certain extent, the artistic charm of this work is based on this dramatic contrast.

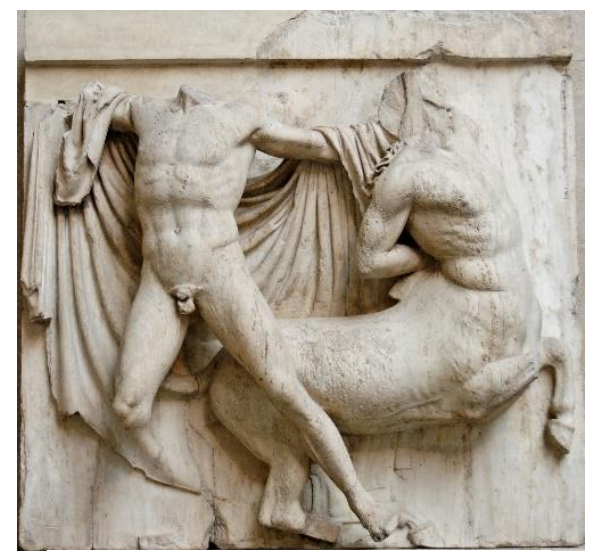

Figure 16. Lapith and Centaur

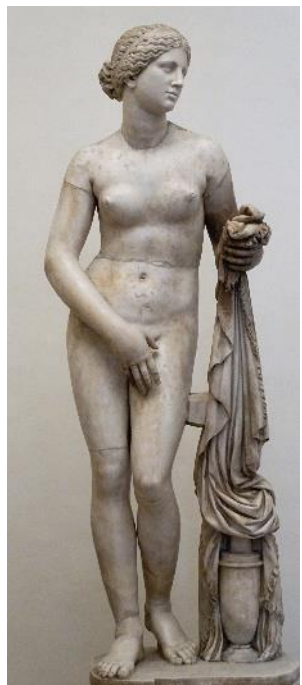

Figure 18. The Ludovisi Cnidian Aphrodite, Roman marble copy (torso and thighs) with restored head, arms, legs and drapery

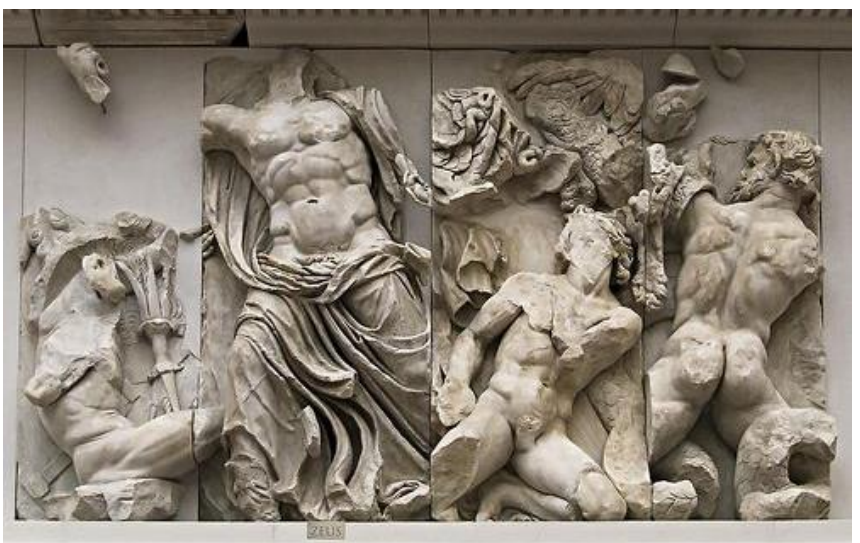

Figure 17. Relief in the Altar of Zeus (c.180-160 BC)

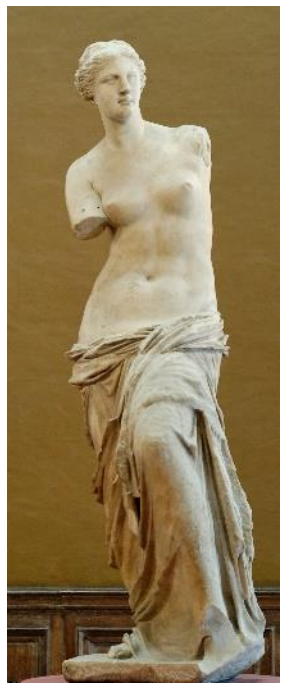

Figure 19. Aphrodite of Milos (c.130-100 BC)

\section{Conclusion}

The drapery in ancient Greek sculpture has undergone style changes from antiquity to classical, and then to Hellenistic style. From conceptual and geometric patterns to realistic and changeable shapes, it has become an indispensable artistic feature of ancient Greek sculpture. It embodies the ancient Greek sculptor's in-depth observation of real life and the expression of ideal beauty, and sets a model of style and quality for later artists to express the relationship between the human body and clothing. It greatly enhances the formal beauty of ancient Greek clothing in plastic art, and makes ancient Greek clothing sublimate from a daily necessities to a material carrier and symbol of classical ideal beauty. 


\section{References}

Harlow, M. (2017). A Cultural History of Dress and Fashion in Antiquity. London: Bloomsbury Publishing.

Hogarth, W. (2010). The Analysis of Beauty. New York: Cosimo Classics.

Hollander, A. (1993). Seeing Through Clothes. Oakland:University of California Press.

Lee, M. (2005). Constructing Gender in the Feminine Greek Peplos. In L. Cleland et al. (Eds.), The Clothed Body in the Ancient World (pp. 59-61). Oxford: Oxbow Books.

Osborne, R. (1998). Archaic and Classical Greek Art. New York: Oxford University Press.

Winckelmann, J. J. (Translated by H. Fusseli, 1765). Reflections on The Painting and Sculpture of The Greeks (p. 28). London: Printed for the Translator, and sold by A. Millar.

\section{Copyrights}

Copyright for this article is retained by the author(s), with first publication rights granted to the journal.

This is an open-access article distributed under the terms and conditions of the Creative Commons Attribution license (http://creativecommons.org/licenses/by/4.0/). 